\title{
Charge-tagged ligands derived of 1,3-imidazolium ion as catalyst precursor of copper, nickel and palladium
}

\author{
Felipe F. D. Oliveira, ${ }^{\star}$ Priscila M. Lalli, Eduardo M. Schmidt, Peter Bakuzis, \\ Alexandre A. M. Lapis, Marcos N. Eberlin, Brenno A. D. Neto \\ Laboratory of Medicinal and Technological Chemistry, Chemistry Institute, University of Brasília (IQ-UnB). \\ *felipefeitosa.oliveira@gmail.com
}

Keywords: Charged tags, Mass spectrometry, Catalysis

\section{INTRODUCTION}

ESI-MS is a soft ionizing technique, ${ }^{1}$ which may allow an online monitoring of a plethora of reactions. Valuable information such as coordination, oxidation states of metal center and others may be obtained by ESI-MS.

Based on that, we synthesized a charge-tagged ligand as a precursor to an in situ formation of a charge-tagged catalyst palladium, cooper and nickel. Herein, we describe the gas phase chemistry of the palladium-derivatives.

\section{RESULTS AND DISCUSSION}

All metal derivatives were synthesized in situ using a charge-tagged acetic acid (Scheme 1).

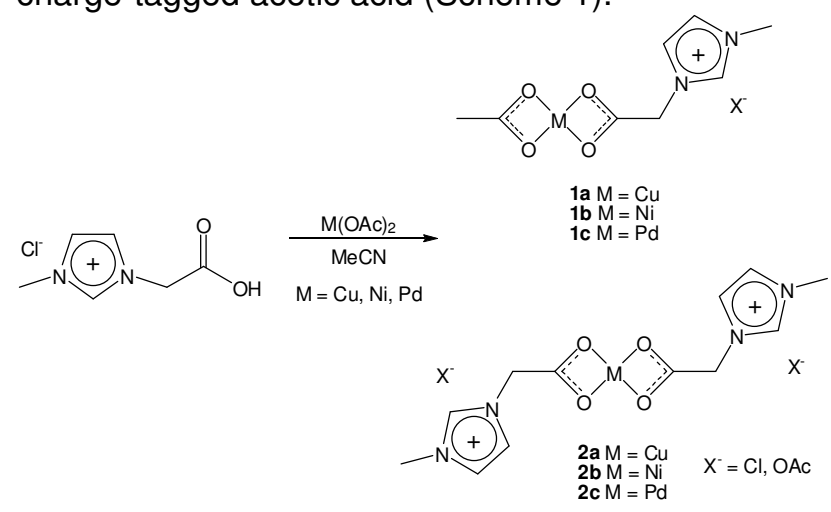

Scheme 1. Mono and doubly charge-tagged complexes expected to be generated in situ.

The monitoring of the reaction with palladium by $\mathrm{ESI}(+)-\mathrm{MS}(\mathrm{MS})$ allowed the detection and characterization of two sets of abundant: $\mathrm{m} / \mathrm{z} 304$, corresponding to the mono-charged 1c, and that of $\mathrm{m} / \mathrm{z} 445$ corresponding to the doubly charged 2c associated to an $\mathrm{OAc}^{-}$anion, that is, [2c.OAc] $]^{+}$.

In the mono-charged species 1c, it is observed the loss of the acetate radical. The doubly charged species 2c (Figure 1) shows the loss of an acetate radical, indicating that the acetate radical is directly linked to the metal center, as shown Scheme 2.

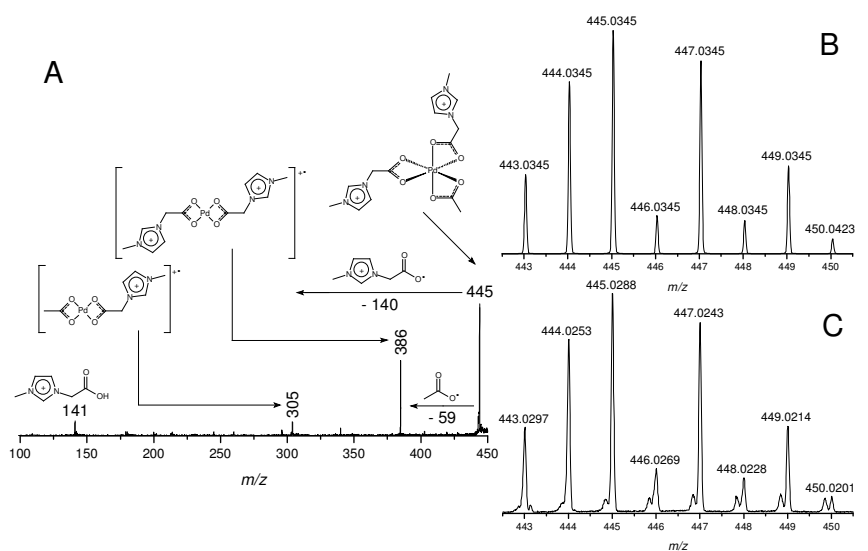

Figure 1. (A) $\mathrm{ESI}(+)-\mathrm{MS} / \mathrm{MS}$ of $[2 \mathrm{c} . \mathrm{OAc}]^{+}$of $\mathrm{m} / \mathrm{z} 445$ and its (B) calculated and (C) experimental isotopologue patterns.

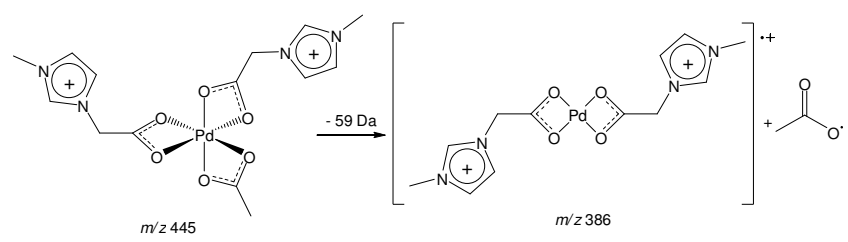

Scheme 2. Possible route for dissociation of [2c.OAc $]^{+}$.

Moreover, some coordinating solvent (acetonitrile) species could be detected and characterized by ESIMS.

\section{CONCLUSION}

The use of a charge-tagged ligand allowed an interesting chemistry for its palladium complex in the gas phase and helped towards a better understanding of some catalytic active species generated using palladium derivatives.

\section{ACKNOWLEDGEMENTS}

FAPDF, CAPES and CNPq are acknowledged for partial financial support.

\section{REFERENCES}

${ }^{1}$ R. G. Cooks, H. Chen, M. N. Eberlin, X. Zheng, W. A. Tao, Chem. Rev. 2006, 106, 188-211. 